\title{
APPLICATION OF EXPLORATORY SPATIAL TECHNIQUES IN THE IDENTIFICATION OF TOURISM HOTSPOTS IN THE AEGEAN REGION OF TURKEY
}

\author{
Asma Rafique $^{1 *}$, Ismail Rakıp Karaş ${ }^{1, a}$, Sohaib K. M. Abujayyab ${ }^{2}$, Ashfak Ahmad Khan ${ }^{2}$,Emrullah Demiral \\ 1DDepartment of Computer Engineering, Karabuk University Turkey. asmamscs@gmail.com, irkaras@gmail.com, \\ emrullahdemiral@gmail.com \\ 2Department of Geography, Karabuk University, Turkey. sjayyab@karabuk.edu.tr; ashfakgeo@gmail.com
}

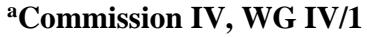

KEY WORDS: Exploratory Spatial Analysis, Autocorrelation, Hotspot Analysis, Tourism, The Aegean Region

\begin{abstract}
:
Exploratory Spatial Analysis Techniques (ESDA) have become popular to identify the spatial association of different variables in many fields of natural and social sciences. The application of Global Moran's I statistics enables us to provide visual insights of spatial data. It helps to detect spatial patterns and hotspots of an activity or process, based on spatial autocorrelation. This study aims to investigate the spatial dependence of domestic and inbound tourist arrivals to 123 cities of all eight provinces of the Aegean Region of Turkey. For analysis, city-level data about domestic and inbound tourist arrivals during 2015-2019 is collected from the Turkish Ministry of Culture and Tourism and is converted to logarithm form to avoid any skewness. The Arc GIS and GeoDa programs are employed for the analysis of spatial autocorrelation and visualization of hotspots of tourist flows in the regions. The results of the study reveal that tourist flows in the region are concentrated in the coastal areas, while inland cities receive an insufficient number of tourists. The hotspots of tourist flow are located mostly in the coastal towns of the provinces of Izmir, Aydın, and Muğla. The study is significant in the provision of useful information regarding resource allocation to the tourism hotspots and the implication of sustainable tourism policy to better utilization of tourism potential.
\end{abstract}

\section{INTRODUCTION}

The advent of innovative analytic techniques with modern computer-aided programs has provided ample opportunities for big data handling in multiple scientific fields of research. In recent decades, growing concern towards georeferenced data and spatial analysis is observed with testing and inquiring new methods to reveal spatial processes. Geographic Information System (ArcGIS) and GeoDa have become popular and extensively used tools for analyzing the distribution, measurement, relationship visualization, and presentation of spatial data(Anselin, Syabri, and Kho 2006). Exploratory Spatial Data Analysis (ESDA) as part of Spatial Statistics enables us to understand the extent of a variable of interest over space, the components of heterogeneity and homogeneity, visualization of clusters, and exploration of hotspots. ESDA provides the measures of spatial autocorrelation to determine the relationship between adjacent spatial units (coded with a single variable), which is essential to capture the degree of similarities and differences among the variables(Anselin 1999). This methodology is adopted in the scope of many empirical studies of diverse scientific disciplines with different variables to provide useful insights.

The use of spatial analytic techniques has also gained importance in tourism research as the subject is directly related to the spatial components of the natural environment. International tourism has emerged as a major source of exchange earnings and local development that provides new chances for income diversification and job opportunities(Brida, Cortes-Jimenez, and Pulina 2016; Martins, Gan, and Ferreira-
Lopes 2017). The advent of tourism as a cheaper source of investment has evoked to formulate the economic policies with greater attention to the tourism sector in many areas of the world. As a result, the tourism industry is progressively growing, securing a prominent position in the national economic agendas of the developing and developed countries. However, the rapid growth of global tourism and associated socioeconomic and environmental consequences have put a big question mark on the future of sustainability. Therefore, continued research on the evaluation of spatial patterns, resource allocation, and priority areas for tourism development is the need of the time for robust policy formation regarding sustainable tourism development.

The tourism industry in Turkey has evolved into a primary source of foreign exchange earnings since the implication of the tourism incentive law of the 1980s (Göymen 2000). The country ranked $6^{\text {th }}$ in the top inbound tourist destinations of the world, with more than 45 million tourist arrivals and 41.1 billion $\$$ tourism receipts in the year 2019 (WTTC, 2020). Tourism development is concentrated in the western and southwestern regions of Turkey in terms of inbound tourist arrivals because of the spatial association of certain socioeconomic and geographical factors. Mass growth of tourism in the already crowded areas is also accompanied by various problems that hinder the motive of sustainable tourism development in the country(Tosun 2001). Besides, the clustering of tourism activities in a specific part of the country also quarterbacks the regional disparities regarding economic development(Khan 2018). Several studies are focusing on the economic and financial aspects of tourism in the country. However, most of the previous studies do not give much attention to the spatial

\footnotetext{
${ }^{*}$ Corresponding Author
} 
patterns of tourism growth and the development of tourist hotspots in the tourist destinations of the country.

The present study is aimed to identify the spatial patterns of inbound and tourist flows in 123 cities of the Aegean Region of Turkey from 2015 to 2019 by employing ESDA techniques. Besides, the study seeks to determine the hotspot of tourist activities in the region and possible change over time. At the same time, the significance maps and scatter plots for visualization of similarities and differences among different tourist destinations of the regions have also been plotted by the application of spatial autocorrelation techniques. The findings are useful for adequate resource allocation in the areas of primary tourist activities. Similarly, the results also contribute to policy implications by determining the changes in the spatial patterns of domestic and inbound tourist flows over time. The results provide detailed insights about the dynamics of tourism in the study area for better planning according to perspectives of sustainable tourism development. As most of the tourismrelated studies do not pay attention to the spatial aspect, the present study contributes to filling the gap in the literature on tourism by providing useful information about the spatial dependence of tourism in the Aegean Sea Region of Turkey.

\section{LITERATURE REVIEW}

The review of literature has revealed the use of Exploratory Spatial Data Analysis (ESDA) in many distinct areas of investigation as a vital tool to measure spatial variations of different variables(Blazquez and Celis 2013; Gomes, Cunto, and Silva 2017; Nawaz et al. 2019). Some recent empirical studies have employed the technique in tourism research to identify the flow patterns of tourist movement and hotspots of concentrated tourist activities. (Stankov et al. (2017) determined the pattern of tourist arrivals in Serbia using spatial autocorrelation analysis on municipality level data. The study provided useful information regarding changes in the trends of spatial variation and inequality in the distribution of tourist flow in the study area. Similarly, Chhetri et al. (2013) explored the clusters of tourism and hospitality employment in Australia using the spatial autocorrelation technique. Their study revealed the presence of five primary clusters of tourism and hospitality that can serve an important basis for future business in tourism. Yang and Wong (2013) employed spatial autocorrelation analysis to identify the dynamics of tourism in 341 cities of China. They found significant positive autocorrelation among the cities of higher tourist values that were located near the beaches and islands. They discussed the presence of inequality regarding tourism in China.

In another study in China, Hu, Neelam, and Green (2016) employed a spatial autocorrelation technique to analyze the spatial dependence and association of tourists in central cities. They found strong positive autocorrelation among tourist destinations and highlighted four critical tourist hotspots based on the values of tourist arrivals. Again, Chhetri et al. (2017) conducted empirical research to identify the clusters of tourism employment by applying spatial econometric approach and spatial autocorrelation analysis. They found higher employment clusters of the tourism operation sector in the rural areas while tourism service employment clusters in the urban areas of Australia. Yang et al. (2013) employed spatial autocorrelation and spatial cluster techniques to find out the tourism dynamics in China. They found that the tourism economy is highly clustered in China, and there was strong spatial dependence in tourist destinations. In a recent study, Xu et al. (2020) conducted empirical research to evaluate the effects of haze pollution on the arrival of international tourists in China. The spillover effects were tested by employing a spatial autocorrelation test. The study concluded that there was a significant positive effect of autocorrelation on the determination of tourism demand in the selected region of China.

Khan (2018) has determined the spatial association of inbound and domestic tourists in 81 provinces of Turkey from 2006 to 2016 by employing ESDA. The study concluded some policy implications for the presence of strong autocorrelation in tourism activities in western and southwestern parts of the country depicting the inequality of tourism development. However, the province-level data in the study might not show the extent of variations in a full manner. Despite some important studies on tourism conducted in various parts of the world using ESDA, the technique is seldom applied in the Turkish tourism sector. Therefore, a literature gap is observed in tourism studies with a special focus on spatial parameters. There is a strong need for testing innovative methods with the help of more advanced analytic tools to help understand the spatial extent of tourism in Turkey as the country is an important tourism destination in the world. The present study tries to fill the research gap by employing ESDA techniques in the tourism sector to yield robust results for future policy formulation.

\section{RESEARCH METHODOLOGY}

The present study has employed the Exploratory Spatial Data Analysis technique to find out the presence of spatial autocorrelation in domestic and inbound tourist patterns of different cities in the Aegean Region of Turkey. Spatial autocorrelation is defined as a measure of geographical proximity and relationship among the variables of nearby localities. The notion of spatial autocorrelation is closely associated with Tobler's First Law, according to which, 'Everything is related to everything else, but near things are more related than distant things' (Tobler 1970, p.234). Moran's I statistics is considered as the most frequently adopted measurement of autocorrelation that has been tested in various empirical studies. The goal of Moran's I statistics is to find the correlation of a variable with itself and against the spatial weight matrix instead of correlation among different variables. The statistical measurement of Moran's I depend on the weighted spatial matrix with variables of $\mathrm{p}$ and $\mathrm{q}$. The measure is done by determining the location and value of variables. The formula of global Moran's I is given as follows (Cliff and Ord, 1981).

$$
\operatorname{Moran} I=\frac{N}{\beta_{0}} \frac{\sum p \sum q\left(w_{p, q}\right)\left(Y_{p} Y_{q}\right)}{\sum p y_{p}^{2}}
$$

In the equation, the total number of variable properties is described by $N$, which is the total number of cities in the present study. The symbol $\beta_{0}$ represents the aggregate of all of the spatial weights of the variable properties, $w_{p, q}$ is spatial weights of city $p$ and $q$, while $y_{p}$ denotes the deviation of the log number of tourist arrivals. The global statistics of Moran's I only describe the presence of spatial autocorrelation and does not depict the location of clusters of variable activities. Therefore, the Local Indicator of Spatial Autocorrelation (LISA) is required to explore the clusters of variable activities. The formulized representation of LISA statistics is given as follows.

$$
\text { LISA } I=\frac{p}{\sum p^{2}} \sum b w_{p, q}(2)
$$


The spatial autocorrelation measure varies between the values of -1 and +1 . A positive value nearing 1 indicates a strong positive correlation, while a negative value nearing -1 depicts a strong negative correlation. The likelihood of equal observation in the data is measured through the Mote Carlo permutation approach. For this purpose, the re-estimation of LISA statistics was performed for each permutation after shuffling the observed values in all locations randomly. Besides, a reference distribution was also created through the application of 9999 random permutations to determine the significance level of LISA. The yearly data of domestic and inbound tourist arrivals of the Aegean Region of Turkey was collected for a period from 2015 to 2016. The data was collected from the yearly bulletins of the Turkish Ministry of Culture and Tourism. All the statistical data were converted to logarithm form to avoid any skewness that may yield misleading results. The software of ArcGIS 9.4 and GeoDa were used for the analysis.

\section{RESULTS AND DISCUSSION}

The analysis started with the making of choropleth maps of domestic and inbound tourist arrivals in the region (Figure 1). The choropleth map of the tourism distribution has depicted the core and periphery patterns in which some core areas of tourism activities are found surrounding the low values of the tourist arrivals. However, choropleth maps cannot depict the clusters of low and high tourist flows; neither can show the presence of spatial association and dependence of tourism in different cities of the region. Therefore, spatial statistics tools are used to determine the relationship of other areas in the context of high and low numbers of tourist arrivals. It is assumed that the high values of tourists surround the region with high tourist flow in the adjacent areas. The assumption is based on the already mentioned law, which described the similarities and differences of different areas based on the degree of nearness. For this purpose, the Spatial Autocorrelation test was conducted to figure out the values of Moran's I statistics.

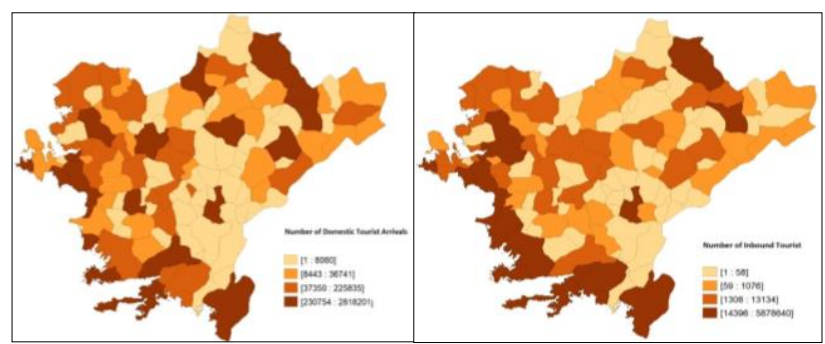

Figure 1. The choropleths maps of domestic and inbound tourist arrivals

The values of Moran's I statistics show positive and significant autocorrelation among the cities with higher tourist arrivals (Table 1). The autocorrelation is found more substantial in arrivals of inbound tourists as compared to the domestic arrivals. Besides, the values of statistics for different years also show the change over time. The inbound tourism has shown positive and strong values in the years of 2015 and 2016 while delivering a slight decrease in later years. This result shows a decline in the clustering of tourist activities in the region that might be related to the development of new tourist destinations attracting foreign tourists. On the other hand, the domestic tourist arrivals have shown an increasing trend of spatial dependence with time. Domestic tourism in Turkey is dispersed to other areas of the region too. Therefore, the clustering of domestic tourists is less as compared to inbound tourists. However, the results of Moran I show an increasing tendency of domestic tourist clusters in the region.

\begin{tabular}{|l|l|l|l|l|}
\hline \multirow{2}{*}{ Years } & \multicolumn{2}{|l|}{ Domestic Tourist } & \multicolumn{2}{l|}{ Inbound Tourists } \\
\cline { 2 - 5 } & $\begin{array}{l}\text { Moran I } \\
\text { Value }\end{array}$ & P- Value & $\begin{array}{l}\text { Moran I } \\
\text { Value }\end{array}$ & P-Value \\
\hline 2019 & 0.238 & 0.001 & 0.122 & 0.02 \\
\hline 2018 & 0.240 & 0.001 & 0.11 & 0.02 \\
\hline 2017 & 0.237 & 0.001 & 0.127 & 0.01 \\
\hline 2016 & 0.308 & 0.001 & 0.171 & 0.003 \\
\hline 2015 & 0.311 & 0.001 & 0.085 & 0.06 \\
\hline
\end{tabular}

Table 1: The Moran's I values for domestic and inbound tourist arrivals

The values of Moran's I statistics can only show the presence of spatial association and strength of the relationship. However, it cannot help visualizing the locations of the clusters of tourist activities. The LISA test was performed to develop significance maps about the clusters and hotspots of the domestic and inbound tourist arrivals in the region. Besides the visualization of clusters, the maps of different years also show a change in the clusters of tourism. The difference is associated with the development of new tourist destinations or sites of attraction dues to which a large number of tourists visit other areas. As mentioned earlier in the discussion of Global Moran's I statistics, the domestic tourist arrivals have shown very weak,

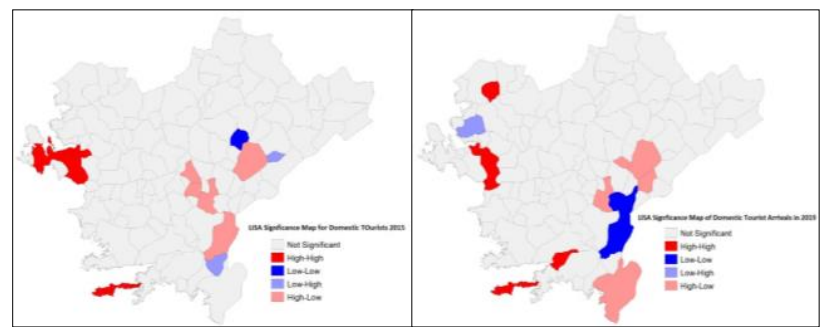

although positive, correlation. The significance maps of 2015 and 2019 also validate the results in visual form.

Figure 2. The Moran's significance maps for domestic tourist arrivals (2015 and 2019)

The maps of significance show the change in the domestic tourist clusters over time (Figure 2). The western parts of the region, including the province of Izmir, have shown a decline in the clustering of domestic tourist activities. However, the province of Muğla has shown a slight increase in the high clustering of tourist arrivals. On the other hand, the significance maps of inbound tourist arrivals show a strong correlation and high clusters of tourist activities in the region (Figure 3 ). Besides, a change in the clusters of inbound tourists is also observed over time. That might explain the reason for the slight decline in the values of Moran's I in recent years. The inbound tourist flows are showing clustering in the new cities of Izmir province. Additionally, the province of Aydin has also demonstrated the emergence of new inbound tourist clusters in the year 2019. Similarly, new clusters are also observed in the province of Mugla. 


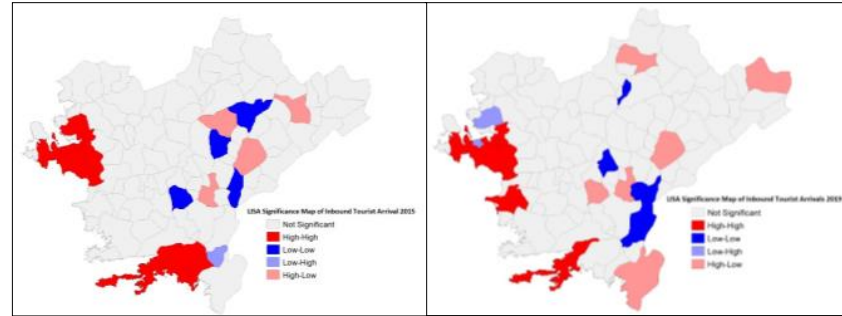

Figure 3. The Moran's significance maps for inbound tourist arrivals (2015 and 2019)

\section{CONCLUSION}

The present study has applied the Exploratory Spatial Analysis (ESDA) techniques by using ArcGIS and GeoDa to analyze the spatial patterns of inbound and domestic tourist arrivals in the Aegean Region of Turkey. The autocorrelation analysis has revealed the strong and positive spatial association of inbound tourist arrivals in the cities of the region. Besides, a change in the spatial dependence of inbound tourist arrivals is also observed over time with the emergence of new tourist clusters in the region. However, domestic tourist arrivals do not show strong autocorrelation, although the value statistics are positive. Meanwhile, an increasing trend in the clusters of domestic tourists is observed in the region. The results of the study provide insights into the tourist flows and changes in the spatial association of tourist clusters. It is expected that the findings of the present study will provide useful information for future resource allocation in the region regarding tourism development.

\section{REFERENCES}

Anselin, Luc. 1999. "Interactive Techniques and Exploratory Spatial Data Analysis." : 253-66. http://www.geos.ed.ac.uk/ gisteac/gis_book_abridged/files/ch1 7.pdf.

Anselin, Luc, Ibnu Syabri, and Youngihn Kho. 2006. "GeoDa: An Introduction to Spatial Data Analysis." Geographical Analysis 38(1): 5-22.

Blazquez, Carola A., and Marcela S. Celis. 2013. "A Spatial and Temporal Analysis of Child Pedestrian Crashes in Santiago, Chile." Accident Analysis and Prevention 50: 304-11. http://dx.doi.org/10.1016/j.aap.2012.05.001.

Brida, Juan Gabriel, Isabel Cortes-Jimenez, and Manuela Pulina. 2016. "Has the Tourism-Led Growth Hypothesis Been Validated? A Literature Review." Current Issues in Tourism 19(5): 394-430.

Chhetri, A., C. Arrowsmith, P. Chhetri, and J. Corcoran. 2013. "Mapping Spatial Tourism and Hospitality Employment Clusters: An Application of Spatial Autocorrelation." Tourism Analysis 18(5): 559-73. http://openurl.ingenta.com/content/xref?genre=article\&issn $=10$ $83-5423 \&$ volume $=18 \&$ issue $=5 \&$ spage $=559$.

Chhetri, Anjali, Prem Chhetri, Colin Arrowsmith, and Jonathan Corcoran. 2017. "Modelling Tourism and Hospitality Employment Clusters: A Spatial Econometric Approach." Tourism Geographies 19(3): 398-424. https://doi.org/10.1080/14616688.2016.1253765.

Gomes, Marcos José Timbó Lima, Flávio Cunto, and Alan Ricardo Silva. 2017. "Geographically Weighted Negative
Binomial Regression Applied to Zonal Level Safety Performance Models." Accident Analysis and Prevention 106(February): https://doi.org/10.1016/j.aap.2017.06.011.

Göymen, Korel. 2000. "Tourism and Governance in Turkey." Annals of Tourism Research 27(4): 1025-48.

Hu, Xi-sheung, C Neelam, and Gary Green. 2016. "Spatial Analysis of International Tourism Growth in China's Cities." Current Politics and Economics of Northern and Western Asia 25(2): 149-75. https://search-proquestcom.libproxy.murdoch.edu.au/docview/1903327216?pqorigsite $=$ summon $\&$ accountid $=12629 \&$ selectids $=10000039,1006$ 985,10000155 .

Khan, Ashfaq Ahmad. 2018. "The Spatial Distribution and Relationship of Tourist Flow in Turkey." European Journal of Tourism Research 19: 40-55.

Martins, Luís Filipe, Yi Gan, and Alexandra Ferreira-Lopes. 2017. "An Empirical Analysis of the Influence of Macroeconomic Determinants on World Tourism Demand." Tourism Management 61: 248-60. http://dx.doi.org/10.1016/j.tourman.2017.01.008.

Nawaz, Zain et al. 2019. "Temporal and Spatial Characteristics of Precipitation and Temperature in Punjab, Pakistan." Water (Switzerland) 11(9): 1-23.

Stankov, Uglješa et al. 2017. "Spatial Autocorrelation Analysis of Tourist Arrivals Using Municipal Data: A Serbian Example." Geographica Pannonica 21(2): 106-14.

Tosun, Cevat. 2001. "Challenges of Sustainable Tourism Development in the Developing World: The Case of Turkey." Tourism Management 22(3): 289-303.

$\mathrm{Xu}$, Dong, Zhenfang Huang, Guolin Hou, and Chen Zhang. 2020. "The Spatial Spillover Effects of Haze Pollution on Inbound Tourism: Evidence from Mid-Eastern China." Tourism Geographies 22(1): 83-104. https://doi.org/10.1080/14616688.2019.1612464.

Yang, Hong, Xiaoya Dong, Min Wang, and Yu Guo. 2013. "GIS-Aided Evolvement Analysis of Spatial-Temporal Pattern of Regional Tourism Industry Environment." 731: 4690-93.

Yang, Yang, and Kevin K.F. Wong. 2013. "Spatial Distribution of Tourist Flows to China's Cities." Tourism Geographies 15(2): 338-63. 